\title{
Delamination mechanism of GFRP sheet bonded on the reinforced concrete beams
}

\author{
Rudy Djamaluddin ${ }^{1, *}$, Hijriah $^{2}$, Rita Irmawati ${ }^{1}$, Faharuddin $^{1}$, Rossy T.Wahyuningsih ${ }^{2}$ \\ ${ }^{1}$ Civil Department, Engineering Faculty of Hasanuddin University, Makassar, Indonesia \\ ${ }^{2}$ Doctoral Student of Civil Department, Engineering Faculty of Hasanuddin University, Makassar Indonesia
}

\begin{abstract}
Fiber reinforced polymer (FRP) has been developed to be applied for a strengthening of the deteriorated structures. In the form of a sheet, the FRP may be applied for the strengthening of the structures by bonding it to the concrete surface. Glass composed FRP (GFRP) sheet is most commonly used due to its relatively lower cost compared to the other FRP materials. GFRP sheet is applied externally by bonding it on the concrete surface. The strengthened structures should be monitored periodically to ensure the health of the strengthened structures. Regarding the development of monitoring system of the strengthened structure, it is important to study the delamination phenomenon of the bonded GFRP. Therefore the delamination mechanism is important to be clarified. Many studies have been done to investigate the bonding characteristics of GFRP sheet under direct tensile loading. However, the studies on the bonding characteristics of GFRP sheet on the strengthened beams due to flexural loadings are still limited. A series of concrete beams strengthened with GFRP sheet on extreme tension surface were prepared. The beam specimens ware loaded under four-point bending test gradually up to the ultimate capacity. Results indicated that prior to final delamination, a local delamination occurred which was indicated by the suddenly decreasing of an applied load. The delamination of the GFRP sheet may be initiated by the flexural cracks occurred on the beams.
\end{abstract}

\section{Introduction}

Strengthening technique is a major field that has been developed for repairing or retrofit existing structures. Fiber reinforced plastics (FRP) have been used extensively as an alternative reinforcement material for a strengthening of existing or deteriorated structures. The development of FRP materials has been accepted as an alternative material for the conventional steel reinforcement. Commonly FRP types are glass fiber reinforced plastics (GFRP), carbon fiber reinforced plastics (CFRP), and aramid fiber reinforced plastics (AFRP), respectively. For the application, the FRPs have been developed in the various form, such as rod, grid, plate, and sheet. It has been applied to many purposes for civil engineering structures not only for new structures but also for strengthening of the deteriorated structures.

Research on the application of such materials to concrete structures is being done by many researchers in many fields. The use of fiber materials in the form of Fiber Reinforced Polymer (FRP) for application to the concrete structures offers several desirable attributes, such as resistance to corrosion, high strength, lightweight, and ease of handling [1-3].
For strengthening purposes, the FRP in the form of a sheet may be applied by bonding it to the concrete surface. Glass fiber sheet as shown in Fig.1 is most commonly used due to its relatively lower cost compared to the other FRP materials. The GFRP sheet is bonded to the concrete surface to have its advantages in the flexural action of the beams. GFRP sheet can be effectively used to increase the flexural strength by attaching at the extreme tension surface [3-7]. Therefore, the bonding of GFRP sheet to the concrete surface plays an important role in order to achieve a good mechanical action. The interaction between GFRP sheet and the concrete surface is a key factor to achieve a mechanical flexural action. The failure may occur when the bond stress in the GFRP exceed the bonding capacity. Therefore, the understanding of the delamination mechanism is important to be clarified. Bonding capacity depends on the bonding strength of the GFRP to the concrete surface. 


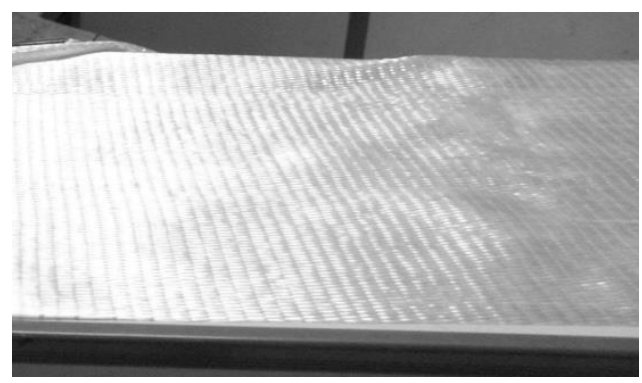

Fig. 1. Glass Fiber Sheet.

In the application of FRP sheet to strengthen a concrete beam that subjected to the flexural loading, the bonding capacity of FRP sheet, as well as its behaviour, may different with the bonding capacity under direct axial loading. In case of flexural strengthened beams, the initiation of delaminating may be induced by the opening of the flexural cracks [8-11].

This study presents a study on the delamination mechanism of the GFRP sheet bonded on a concrete beam due to a flexural load. Table 1 shows the properties of GFRP used in this study [12].

Table 1. Properties of GFRP sheet

\begin{tabular}{|c|c|c|c|}
\hline & $\begin{array}{c}\text { Tensile } \\
\text { strength } \\
(\mathrm{MPa})\end{array}$ & $\begin{array}{c}\text { Tensile } \\
\text { Modulus } \\
(\mathrm{GPa})\end{array}$ & $\begin{array}{c}\text { Laminate } \\
\text { Thickness } \\
(\mathrm{mm})\end{array}$ \\
\hline $\begin{array}{c}\text { Glass Fiber } \\
\text { (SHE-51A) }\end{array}$ & 3240 & 72.4 & 0.36 \\
\hline Epoxy resin & 72.4 & 3.18 & - \\
\hline GFRP & 575 & 26.1 & 1.3 \\
\hline
\end{tabular}

The GFRP used in this study was composed by EGlass and epoxy resin. The GFRP has a tensile strength of $575 \mathrm{MPa}$ with an elastic modulus of $26.1 \mathrm{GPa}$. The bonding strength of the epoxy resin to the concrete based on manufacturer data sheet is $2.12 \mathrm{MPa}$ [13].

\section{Specimens and Test Setup}

\subsection{Specimens}

The specimens were designed as a normal flexural beam with parameters of the strengthened length of GFRP sheet. The specimens were divided into three types, which are strengthened beams on the whole length (BGA Type), strengthened with $75 \%$ of span length (BGB Type) and strengthened beams with $50 \%$ of span length (BGC), respectively, as shown in Fig.2. A series of normal beams were also prepared for comparison. The details of specimens are presented on the Fig.3. The cross-section of beam specimen was $150 \times 200 \mathrm{~mm}$ with the total length of $3300 \mathrm{~mm}$. The concrete beams were cured for 28 days before the application of the GFRP sheet. The cylinders, as well as beam specimens for rupture test, were also prepared to determine the material properties of concrete. Table 2 presents the material properties of the concrete.
The compressive strength of concrete at 28 days was 35 $\mathrm{MPa}$. The Young Modulus and rupture strength of concrete estimated based on concrete compressive strength [**] were $30 \mathrm{GPa}$ and $3.5 \mathrm{MPa}$, respectively.

Application of GFRP sheet was conducted based on the standard procedure of manufacturer. Before the application of GFRP sheet, the bottom surfaces of the beams were smoothed by a disk sander. The epoxy resin was applied to the GFRP sheet placed on the table using a soft roller to impregnate all the fibers in the resin. The epoxy resin was applied to the treated surface using a soft roller before patching of the impregnated GFRP sheet to the treated surface. The GFRP sheet was attached with slight pressure using a soft roller. The beams were then cured again for 3 days to allow the hardening of resin. Fig. 4 shows the preparation of the specimens.

Table 2. Properties of Concrete

\begin{tabular}{|c|c|c|c|}
\hline & $\begin{array}{c}\text { Tensile } \\
\text { strength } \\
(\mathrm{MPa})\end{array}$ & $\begin{array}{c}\text { Compressive } \\
\text { Strength } \\
(\mathrm{MPa})\end{array}$ & $\begin{array}{c}\text { Young } \\
\text { Modulus } \\
(\mathrm{GPa})\end{array}$ \\
\hline Concrete & $3.5^{*}$ & 35 & $30^{*}$ \\
\hline Steel bar & 325 & 325 & 200 \\
\hline
\end{tabular}

*) Estimated

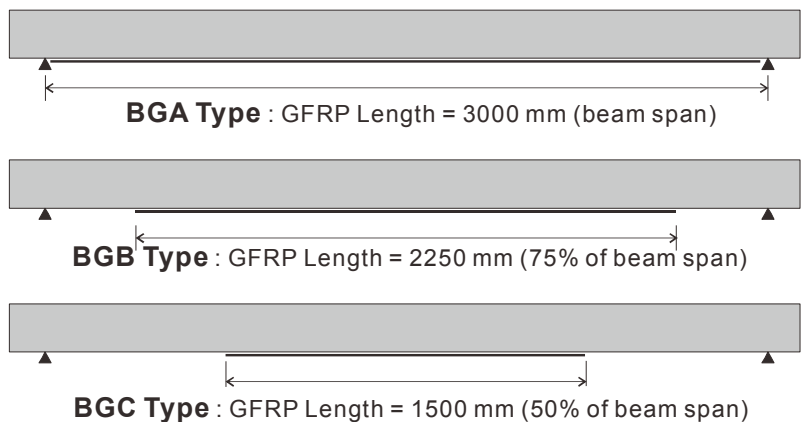

Fig. 2. Type of Specimens

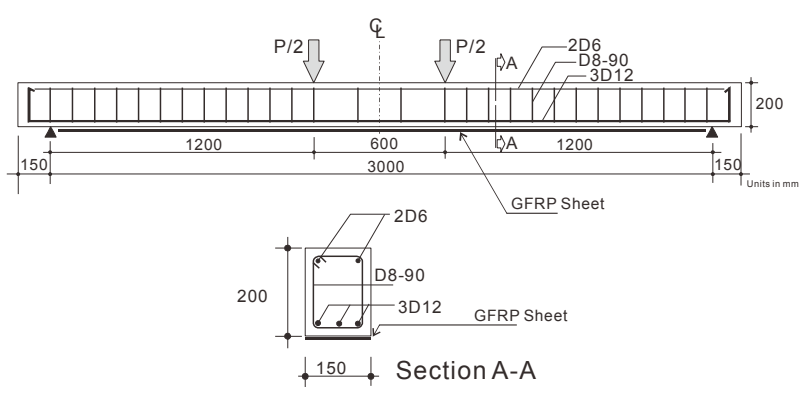

Fig. 3. Detail of Specimen 


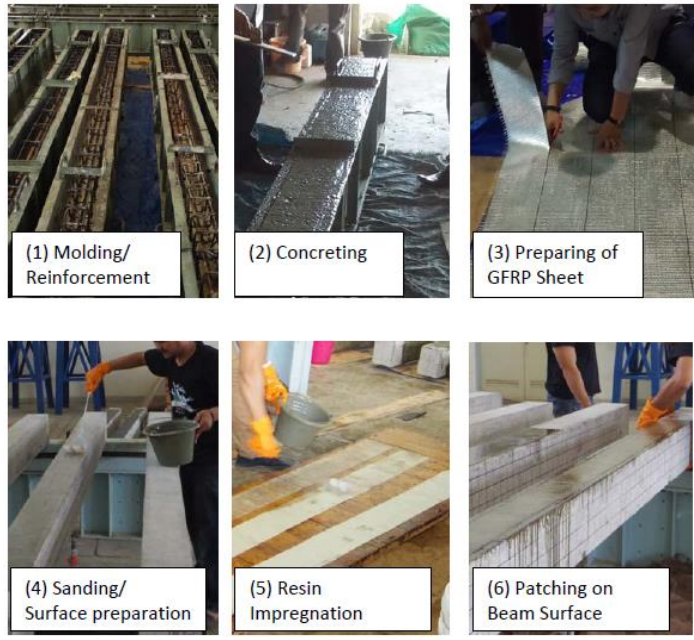

Fig. 4. Specimen Preparation

\subsection{Test Setup}

The beam specimens were tested under simply supported beams subjected to two point load using a universal testing machine, as shown in Fig.5. Each specimen was instrumented by strain gauges on the concrete surface at extreme compression surface, steel reinforcement and on the GFRP sheet, respectively. The deflection and loading were measured using LVDTs and a load cell. The load was applied gradually with a constant rate of $3 \mathrm{kN}$ per minutes up to yielding of steel reinforcement. Further loading was controlled by displacement with the rate of 5 mm per minutes. All instrumentation was connected to a computer-based data logger for data recording. During the loading, the cracks propagation, as well as the delaminating phenomenon, was noted.

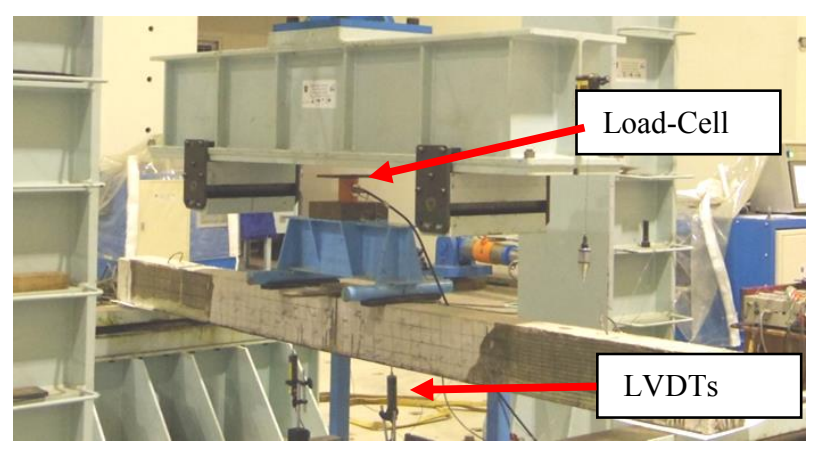

Fig. 5. Loading Set-up

\section{Theoretical Understanding}

The theory of flexure for reinforced concrete is based on three basic assumptions, which are sections perpendicular to the axis of bending that are plane before bending remain plane after bending, The strain in the reinforcement is equal to the strain in the concrete at the same level, and the stresses in the concrete and reinforcement can be computed from the strains by using stress-strain curves for concrete and steel. Therefore, the concrete and the reinforcement must act together to carry load [14]. This assumption implies a perfect bond between the concrete and the steel as well as the GFRP. The strain is linearly distributed along the height of the beam.

For calculation of the reinforced concrete beams flexural capacity, a simple elastic-perfectly plastic model is assumed for the reinforcing steel in tension or compression, as shown in Fig.6a and for the concrete material, the model consists of a parabola from zero stress to the compressive strength of the concrete, as on Fig.6b. The strain that corresponds to the peak compressive stress, is often assumed to be 0.002 for normal strength concrete [14]. The material model of GFRP is simply liner from zero up to rupture, because of the nature of GFRP is an elastic material.

For nominal flexural capacity calculation of reinforced concrete section, an equivalent rectangular concrete stress distribution is adopted [14], shown in Fig.7. The FRP sheet $(A f)$ was assumed that it was full bonded to the concrete surface. Once the bonding stress decreases due to the starting of delamination, then the strain of FRP is not linearly equal to the strain of reinforcing steel. This also influenced the decreasing of the beam flexural stiffness as well as load carrying capacity.

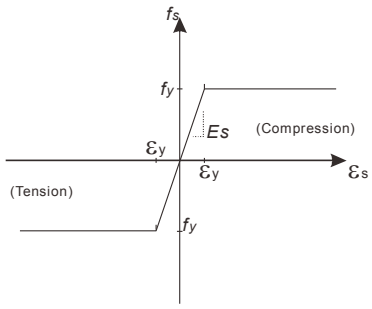

(a) Steel Model

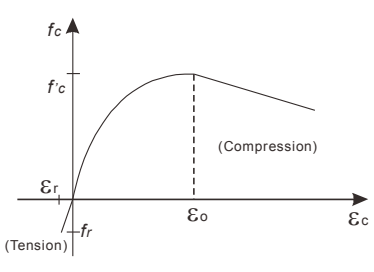

(b) Concrete Model
Fig.6 Material model of Reinforcing Steel and Concrete

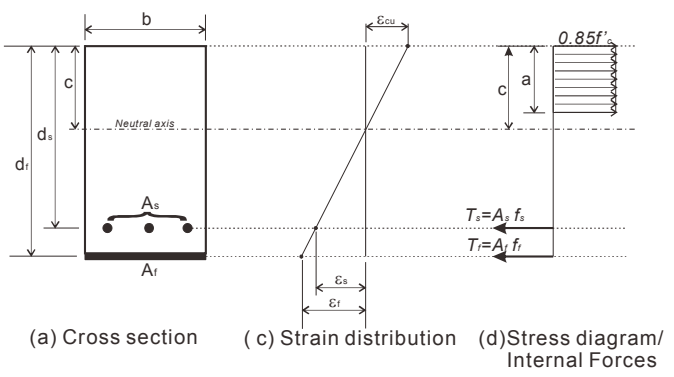

Fig.7 Strain-stress model of reinforced concrete

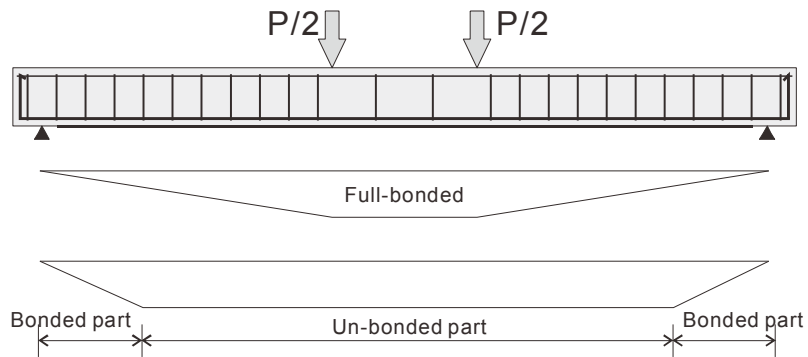

Fig.8 Tensile stress of reinforcement on Bonded and UnBonded beams 
Theoretically, tensile stress diagram along the full-bonded tensile reinforcement is distributed in the similar form with the moment diagram. However, for Un-bonded tensile reinforcement, the tensile stress is distributed constantly along the unbonded length. Fig.8 shows the illustration of tensile stress diagram of unbonded and bonded tensile reinforcement.

\section{Results and Discussions}

\subsection{Load-Deflection Relationship}

The relationship between the applied load and span center deflection is presented in Fig.9. At the initial stage of loading, all beams were un-cracked beams. On the specimens of BN type as well as BG types (BGA, BGB, and $\mathrm{BGC}$ ), the concrete resisted both compression and tension force. When the applied load reached the rupture strength of the concrete on specimens, the concrete started to crack. This caused a decreasing of beam flexural stiffness. Once the tension zone of concrete cracked, its tensile force resistance becomes negligible. The tensile force due to external load was primarily carried by steel reinforcement on BN Types, whereas on the BG Types, the tensile forces were resisted by both steel reinforcement and GFRP sheet reinforcement.

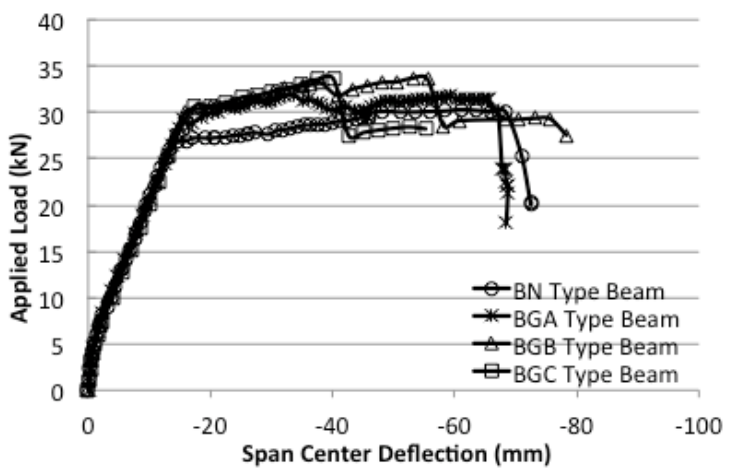

Fig.9 Load-Deflection Relationship

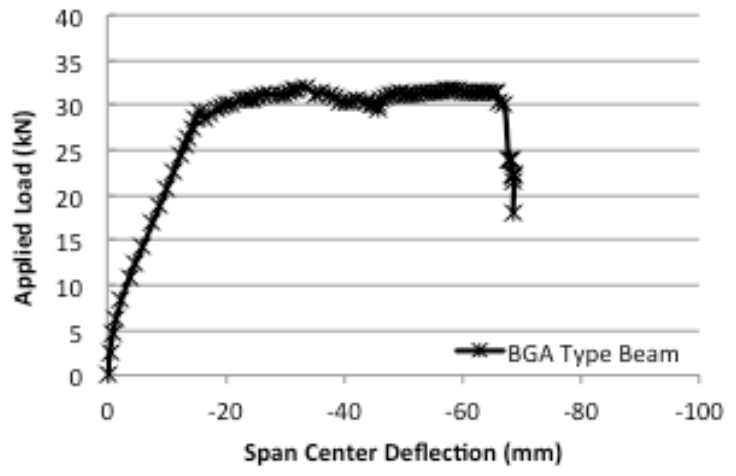

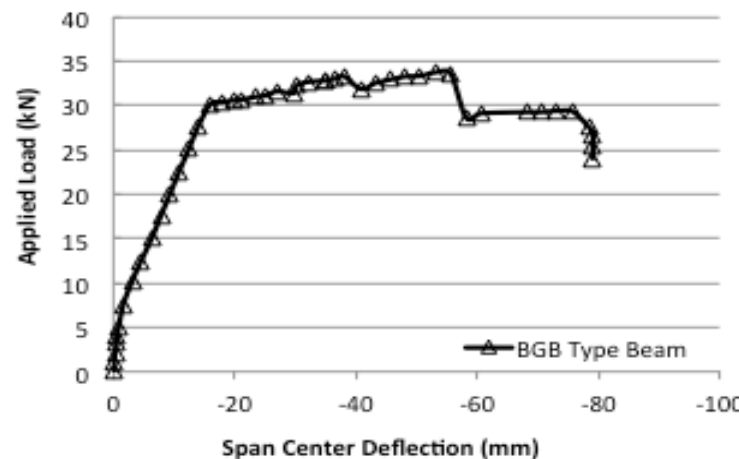

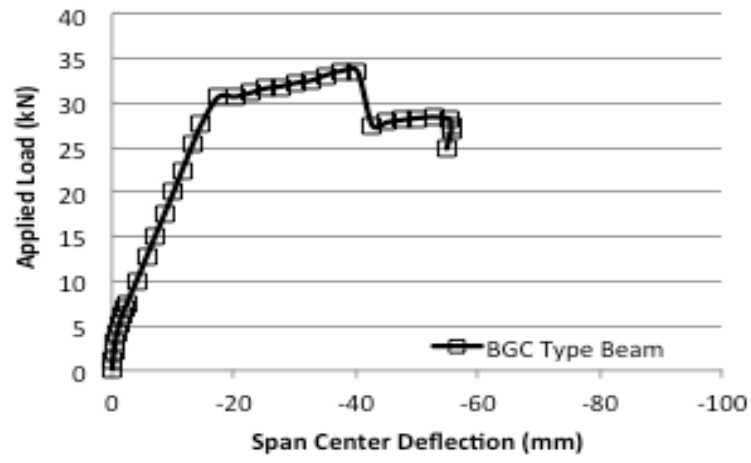

Fig.10 Separated Load-Deflection Graph of each Type

The increasing of applied load was followed by the propagation of deflection up to the yielding point of steel reinforcement. On BN type specimen, the yielding of tensile reinforcement occurred when the applied load reached $27 \mathrm{kN}$. For BG Types, the yielding of tensile reinforcement occurred later when the applied load reached $30 \mathrm{kN}$ due to the effect of the GFRP sheet reinforcement. Further loading, the yielding of tensile reinforcement caused the decreasing significance of the beams flexural stiffness on both specimens. The deflection propagated without significant increase of the load capacity. Post yielding behaviour of BN Type propagated as typical behaviour of steel reinforced concrete beams.

However, on the BG Types, the behaviour was influenced by the GFRP sheet reinforcement. After yielding of steel reinforcement, the additional tension force was carried out by GFRP sheet reinforcement. As long as the GFRP sheet perfectly bonded to concrete surface then the propagation of load-deflection line was still smooth and the applied load tended to increase. However, when a locally delamination occurred, then the decreasing of load capacity occurred. As shown in Fig10, the BGA types with GFRP sheet on whole span length indicated that a local delamination occurred when deflection reached to approximately $40 \mathrm{~mm}$. This caused slightly decreasing of applied load. On the specimen BGB type with shorter bonding length, the phenomenon also occurred and followed next local delamination when deflection reached to approximately $60 \mathrm{~mm}$. However, on the specimen BGC Type with shortest bonding length, the local delamination at approximately $40 \mathrm{~mm}$ of deflection occurred with relatively significant decreasing of applied load compared to the other two types. The specimens failed by final delamination when the deflection reached 
to approximately $60 \mathrm{~mm}$. This observation indicated that the length of bonding influenced to the flexural behaviour especially on the post-yielding stages. The debonding mechanism may be identified based on the load-deflection response in which indicated by the unstable relationships. It should be noted here that the decreasing of the load due local debonding was indicated also by some "ting" sounds.

\subsection{Strain Distribution}

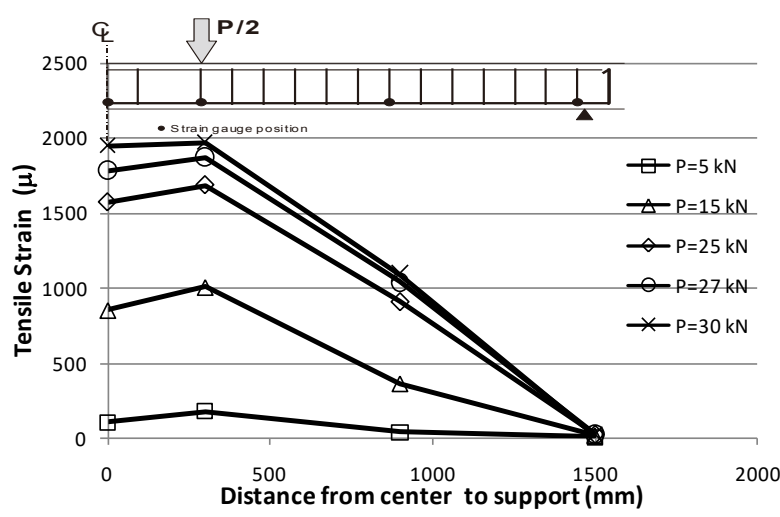

Fig.11 Tensile Strain Distribution of Steel Reinforcement on BN Type

Fig.11 shows the tensile strain distribution of steel reinforcement from the span center to the support. The results were based on the strain gauges patch on the span center $(0 \mathrm{~mm}), 300 \mathrm{~mm}, 900$ and 1500 away from the span center, respectively. As it can be observed that the strain on steel increased as the increase of the applied load. The strain was distributed in the similar form with the moment diagram due to the applied load.

Fig.12 shows the tensile strain distribution on the GFRP Sheet based on the strain gauges attached at the same point with stain gauges patched on the steel reinforcement.

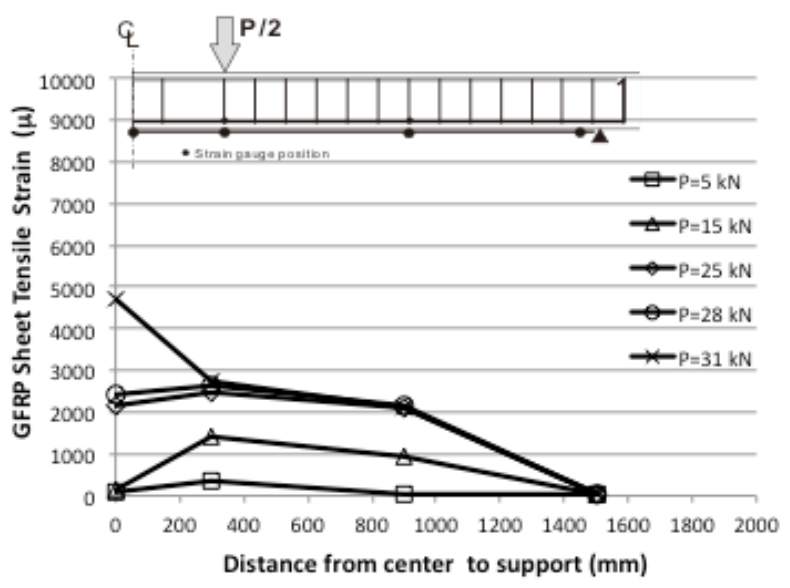

(a) BGA Type

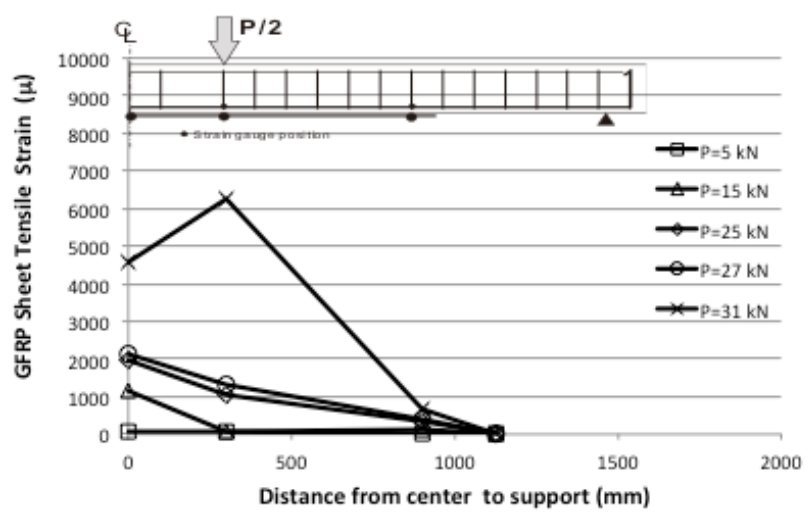

(b) BGB Type

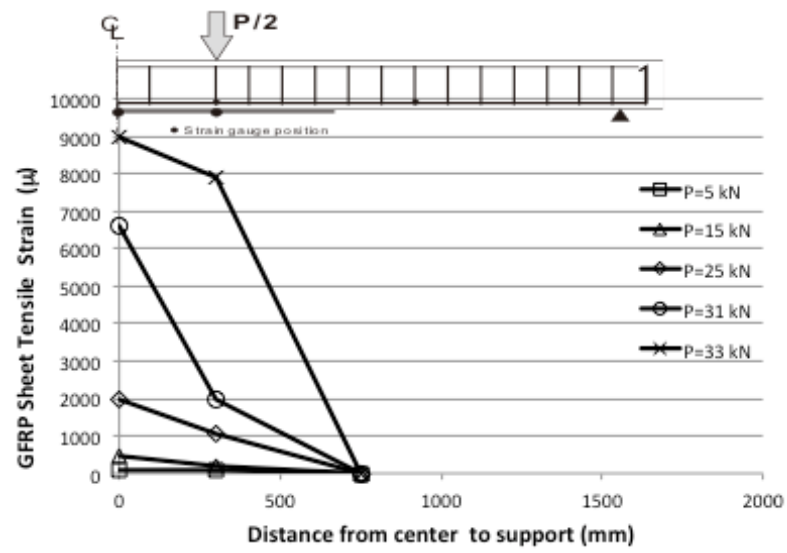

(c) BGC Type

Fig.12 Strain Distribution of GFRF Sheet Reinforcement

The tensile strain of GFRP sheet was distributed maximum on the span center and decreased to approximately zero at the end of reinforcement. The strain distribution was much influenced by the corresponding cracks. Therefore, the distribution form was not as stable as on the tensile steel reinforcement. On the BG types specimens, the strain at the maximum load limited by delaminating. On the specimen BGA, the maximum strain on GFRP on the span center was $5000 \mu$ decreased to almost zero on the end of GFRP sheet. While, the maximum strain of specimen BGB at the span center was $6200 \mu$, and the maximum strain of specimen BGC at the span center was $9000 \mu$.

\subsection{Strain Distribution on Beam Section}

Fig. 13 presents the strain diagram on the span center beams cross-section. At lower load, the strain of the concrete and the strain on the reinforcement was still relatively equal at the same level. On further loading, this phenomenon occurred until the load level prior to delamination. As it can be observed that on the specimen $\mathrm{BN}$, there was a stable strain propagation up to the ultimate load. However, on the BG types specimen, the strain on the GFRP sheet reinforcement at the ultimate level tended not to be equal anymore to the concrete and steel reinforcement at the same level. Prior to final delamination, it was observed that the GFRP sheet strain increased out of the strain equality to the other structural 
elements in the concrete sections. It was noted also that the shorter bonding length tended to have bigger strain jump before final delamination.

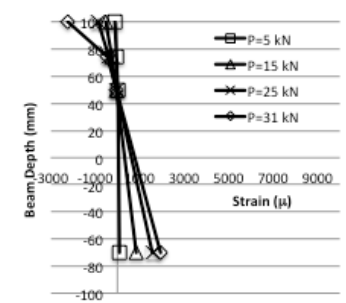

(a) BN Type

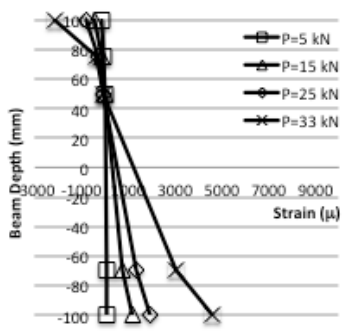

(c) BGB Type

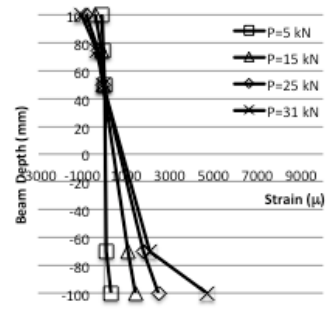

(b) BGA Type

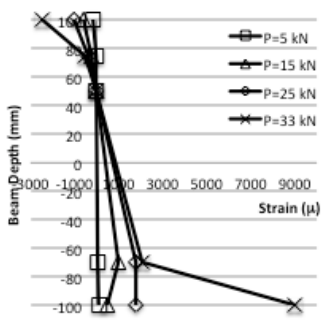

(d) BGC Type
Fig.13 Strain Distribution on Span Centre Cross Section

\subsection{Failure Mode}

Fig.14 presents the photograph of the failed specimens. The ultimate capacity of all BG Type specimens were decided by delamination of the GFRP sheet reinforcement. The occurrence of the final delamination caused the crushing of the compressive concrete in almost same time (just after delamination). As it has been discussed that prior to final delamination, some local delamination occurred which was indicated by some "ting" sounds. This sounds mostly occurred after yielding of steel reinforcement. The local delamination was influenced by the occurred cracks, as illustration on Fig.15. The longitudinal shear stress in epoxy layer between GFRP sheet and the concrete surface was concentrated on the edge of the cracked concrete section. Once this stress exceeded the shear strength of the epoxy layer, then the local delamination occurred. This caused the increasing of the shear stress in epoxy layer on another places as the consequences to maintain the balance. On the stressbalancing cannot be maintained longer then the final delamination occurred.
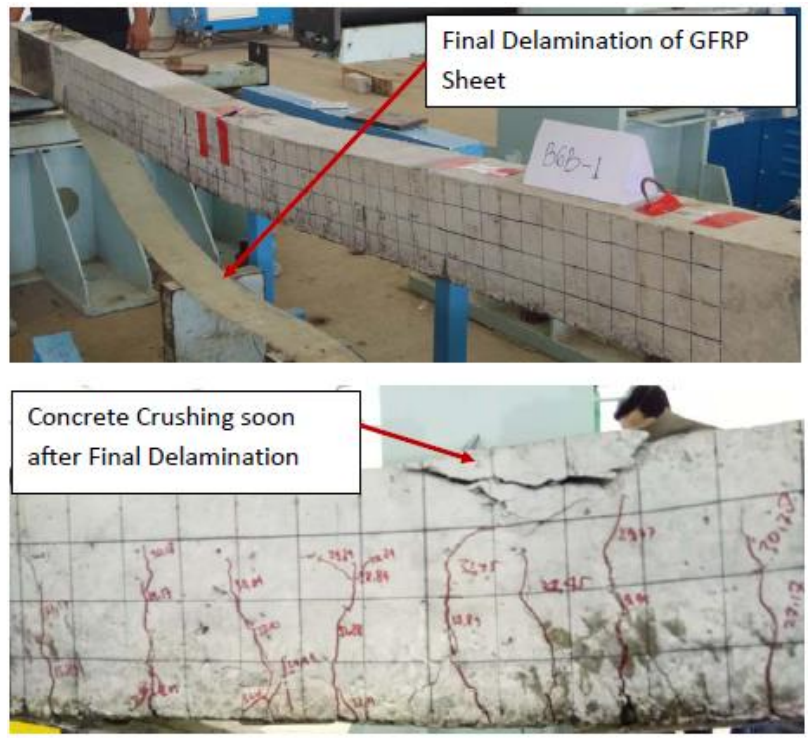

Fig.14 Failed Specimens

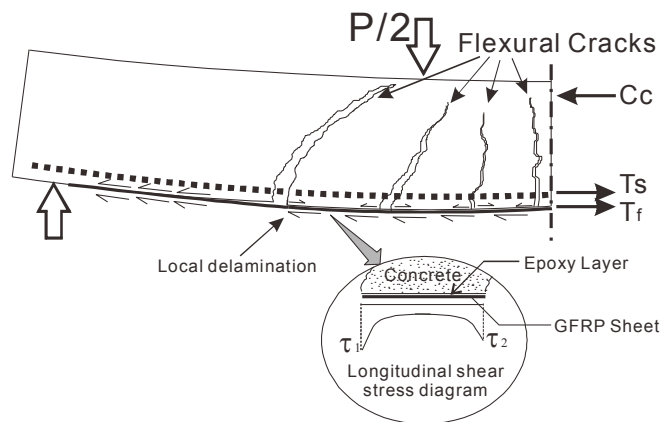

Fig.15 Local Debonding due to Cracks

The authors would like also to acknowledge the member of the Civil Department of Hasanuddin University for them valuable supports in conducting the study. The acknowledgment is extended also to PT. Fyfe Fibrwrap Indonesia for them valuable support and technical assistance during the application of GFRP Sheet.

\section{References}

1. Joseph R.Y., Shawn P.G., David W.D.,Jason J.M "Flexural behavior of concrete beams strengthened with near-surface-mounted CFRP strips“, ACI Struct. J. 104(4): 430-437, (2007).

2. Shin, Y.S and Lee, C., "Flexural Behavior of Reinforced Concrete Beams Strengthened with Carbon Fiber -Reinforced Laminates at Different Levels of Sustaining Loads", ACI Structural Journal,100, 231-239 (2003).

3. Teng, J.G, Chen J.F, Smith S.t and Lam.L, "FRPStrengthened RC Structures, John Wiley \& Sons, West Succex, UK, 266 pp, (2003).

4. Rudy Djamaluddin, Abdul Madjid Akkas, Akristin Eko S, "Application of GFRP sheet for strengthening of yielded reinforced concrete beams", proceeding the 6th Civil Engineering Conference in Asia Region, pp.TS10-9 - TS10-16, Jakarta, (2013).

5. Rahimi H., and Hutchinson, A., "Concrete Beams Strengthened with Externally Bonded FRP Plates", 
Journal of Composites for Construction, ASCE, 5, 44-55 (2001).

6. Balaguru.P, Nanni A, Guancaspro J, FRP Composites for Reinforced and Prestressed Concrete Structures: A guide to fundamentals and design for repair and retrofit, Taylor \& Francis, (2009).

7. Lorenzis, L.D, Miller, B, and Nanni A, "Bond of Fiber-Reinforced Polymer Laminates to Concrete, “ACI Material Journal, 98, 256-264 (2001).

8. Rudy Djamaluddin, Mufti Amir Sultan, Rita Irmawati, and Hino Shinichi, "Bond Characteristics of GFRP Sheet on Strengthened Concrete Beams due to Flexural Loading", 1ACSIT International Journal of Engineering and Technalogy. 7,110-115 (2015).

9. Dong-Uk Choi, Thomas H.K.Kang, Sang-Su Ha, Kil Hee Kim and Woosuk Kim., "Flexural and bond behavior of concrete beam strengthened with hybrid carbon-glass fiber reinforced polymer sheet. ACI Struct. J., 108(1)., pp.90-98, (2011).

10. M.S.Alam, T. Kanakubo and Yasojima, "ShearPeeling Bond Strength between Continuous Fiber Sheet and Concrete", ACI Structural Journal, 109, No.1, Jan.-Feb. , pp.75-82, (2012)

11. Mehdi T.K., and Chris J.B., "Fiber-Reinforced Polymer Bond Test in Presence of Steel and Cracks", ACI Structural Journal, 108, 735-744 (2011).

12. PT.Fyfe Fibrwrap Indonesia, "Test Report for bonding strength Tyfp S + SHE-51", (2013)

13. Fibrwrap Construction Pte.Ltd, "Test Report for testing of shear strength for SEH55H glass fiber", (2003)

14. James K. Wight, James G. Macgregor, "Reinforced Concrete Mechanics and Design", Pearson Education, Inc., New Jersey, (2012). 